\title{
Psychiatry and the Politics of the Underclass
}

\author{
PHILIP THOMAS, MARIUS ROMME and JACOBUS HAMELUNCK
}

\section{The death of community care}

'There they stand, isolated, majestic, imperious, brooded over by the gigantic water tower and chimney combined, rising unmistakable and daunting out of the countryside... For the majority of these establishments there is no appropriate use.'

These grim words delivered in 1961 by Enoch Powell at the first Annual General Meeting of the National Association for Mental Health, convey powerfully the estrangement and fear of mental illness. The speech was said to introduce a new age of tolerance and understanding for the mentally ill. Today it is difficult to sustain the belief that community care has been a success. Some condemn the policy, claiming that it has been adopted uncritically at the expense of long-term care, placing the public at risk (Coid, 1991). Others have demanded a moratorium on deinstitutionalisation (Lamb, 1992). The Glasgow Media Group (Philo et al, 1994) has demonstrated the public stigma of mental illness, with daily newspaper and television reports of 'failures' or 'tragedies' in community care. Set against this clamour, the voices of service users struggle to be heard. Many who use mental health services find the experience overwhelmingly negative. Survivor accounts describe mental health services as 'dehumanising' (Pembroke, 1993). Others articulate the view that, despite its shortcomings, community care is far superior to the asylum system it replaced (Campbell, 1993). Most worrying of all is the deep dissatisfaction with the role of psychiatrists found in a patient survey by Rogers et al (1993). Only $12 \%$ of respondents found psychiatrists helpful. They were described as 'unconcerned', 'lacking understanding' or 'reserved'.

Changes in the mental health act have made it more difficult for psychiatrists to control patients. In 1986 the courts ruled that patients could not be recalled to hospital if they defaulted from medication in the community ( $R$ v. Hallstrom, ER 306, 1986). Demands for a community treatment order by the Royal College of Psychiatrists and the Mental Health Act Commission were opposed by users and community psychiatric nurses. It lives on as the supervision order. The debate about community care is couched in terms of compulsion and coercion (Dyer, 1987), a tendency regarded by some as 'anti-therapeutic', and in contravention of Article 5 of the European Convention on Human Rights (Eastman, 1995). What has gone wrong? Our contention is that community care has failed because the policy has effected nothing more than a geographical shift in the locus of care. It has, as Campbell (1993) implies, disregarded opportunities to change the languages psychiatrists use to talk about mental illness.

\section{The nature of clinical psychiatry}

In Britain we can trace the origins of clinical psychiatry to the social changes which resulted in the Victorian asylums. Psychiatry originated in social policy rather than medical science (Jones, 1991). Once social policy established the medical profession's legitimate interest in mental illness, the asylum system provided the perfect environment to study it. Isolating the insane from society grew out of the Romantic belief in a Utopian society which regarded urbanisation and industrialisation responsible for the growth of insanity. This isolation was linked to the search for medical causes of mental illness, as asylum care isolated the insane from the effects of poverty, overcrowding, alcohol misuse, violence, prostitution and other forms of abuse which characterised industrial urban life. Yet, paradoxically, this sequestration, and the emerging concept of mental illness, devalued the importance of social factors in relation to insanity. Psychiatrists studied mental illness devoid of any social context, producing a schism between the social reality of mental illness and the interpretation of sufferers' experiences. This persists to this day. To understand the consequences of this we must consider two issues: the nature of the medical model in mental illness, and the relationship between mental illness and social factors.

According to Lewis (1936) the medical model in psychiatry never considered mental illness narrowly in terms of disease processes, but as an interaction between environment and individual. Contemporary 
psychiatry faces two problems. First, there has been a shift within the environment-individual dialectic, with greater emphasis placed on biological (individual) models. Second, the relationship be tween society and the individual has been redefined. This, as we shall see, has political, cultural and economic consequences. The medical model assumes that psychiatric symptoms represent different mental illnesses. In this form of biological determinism, subjective experience is only important in that it helps to differentiate between illnesses. Determinism, the belief that everything that happens is determined by preceding events, formed the basis of Newtonian physics and the natural sciences, where its success resulted in its application to the study of the human body and brain, through the work of Helmholtz and others. Determinism in psychiatry, which teeters unsteadily over body and mind, holds that experience, or mental events, arises out of brain events. Subjective experience is of secondary importance to brain events which cause experience to happen.

\section{Cultural contexts}

Psychiatry, like medicine, is a product of culture, and it is inevitable that recent cultural changes have implications for psychiatry. The last 20 years have witnessed an economic revolution in western societies. Service industries have largely replaced heavy manufacturing industry, and there has been a growth in part-time work and a rise in unemployment. The Joseph Rowntree Foundation (1995) reported an increase in inequality in the UK, with the poorest $30 \%$ of the population failing to benefit from the prosperity enjoyed by the majority through the economic reforms introduced by Margaret Thatcher. Inequality in income grew more rapidly in Britain than elsewhere. Wages for the lowest paid hardly changed from 1978 to 1992 , whereas those of better paid workers rose up to $50 \%$. Poverty increased especially in ethnic groups. The most important factor thought to be responsible for these changes was the increase in chronic unemployment. Galbraith (1992) argues that these changes have produced deep divisions between those who work, are affluent and enfranchised, and those who are none of these. He refers to this latter group as the functional underclass. What are the implications of this for psychiatry?

One of the principal objectives of Mrs Thatcher's government was to reduce the influence of the state, which, in her view, had become too powerful at the expense of individual freedom. Private enterprise and individual freedom would create a new economic climate and generate prosperity. A new Culture of the Individual arose like a Phoenix out of the state's ashes, signifying the triumph of an individualistic construction of society over a collectivist one. The National Health Service, state benefits and education, symbolise belief that we have a collective responsibility for the well-being of those members of society less fortunate than ourselves. This has been challenged through reduced personal taxation, changes in benefits, and the imposition of a new set of values on the public sector, the instruments of the state. The motive power behind these changes was a belief in personal responsibility. But there is a corollary to this. If individuals are responsible for their lives, then this must apply when things go wrong. This places the onus for social problems at the door of the individual. Social factors such as poverty and unemployment are held to be irrelevant in understanding individual failure. How does this relate to psychiatry?

\section{Politics and psychiatry}

Most of us assume that politics has no place in understanding disease and illness. Such a view disregards the history of public health medicine, and recent events in psychiatry. The first Public Health Act was passed in 1848, establishing the General Board of Health which collected data on the prevalence of diseases in the population. John Snow demonstrated that the cholera epidemic of 1854 was spread by water some 30 years before the discovery of the responsible organism by Robert Koch. By the end of the 19th century the link between poverty and infant mortality was established, and in the recession of the 1930s, poor nutrition in poverty-stricken communities was linked to a variety of diseases. The public health movement improved the health of the poor by establishing links between poverty and health. There is a more recent precedent for the interleaving of psychiatry and politics. Ten years ago the Royal College of Psychiatrists played an important part in expelling the former Soviet Union from the World Psychiatric Association because of the virulent political abuse of psychiatry in that country. This makes it difficult to support the view that we should keep political and psychiatric discourse apart. If we accept that social and economic factors influence mental health, then it follows that there is a political dimension to mental health. These relationships are complex and take many forms. For example, Warner (1985) has shown that the political economy influences 
outcome in schizophrenia. Here, we are concerned with a different type of relationship, that between poverty and mental illness, for there is evidence that poverty and mental ill-health are related.

In the USA, the New Haven Epidemiological Catchment Area Study found that people living in poverty had twice the risk of a DSM-III Axis I diagnosis than those not in poverty (Bruce et al, 1991). This relationship was particularly strong for those suffering from the most severe disorders. In Nottingham, the WHO study of outcome in severe mental illness found that schizophrenia clustered in the poorest inner-city areas (Giggs \& Cooper, 1987). The TAPS project (Thornicroft et al, 1992) found a fourfold variation in annual accumulation rates for new long-stay patients (between 2.5 to 11.0 per 100000 population) between the least and most affluent London health districts. Over $50 \%$ of the variance in accumulation rates was explained by social deprivation score, and $80 \%$ by local unemployment rates. Of course, these figures beg the nature of the association. The relationship between unemployment and ill health is complex (Bartley, 1994), but this should not prevent an inquiry. Does poverty increase your chances of developing serious mental illness, or, if you develop a serious mental illness, are you more likely to end up living in poverty? Although there are problems in defining homelessness, recent studies suggest there are few demographic differences between the mentally ill homeless and other homeless people (Cohen \& Thompson, 1992). Psychiatry locates the problem of homelessness within a mentally ill individual, rather than in society. The 'drift' hypothesis is a good example of this. It is difficult to sustain a limited view (that psychosis causes homelessness) in view of the growth of social adversity. What are the implications of these relationships?

The medical model understands mental illness in terms of disordered individual functioning. This approach has provided deep insights into the biological basis of psychosis, but by focusing on the individual, it overlooks the importance of social factors. This is emphasised by changes in the nature of psychiatric discourse. Pincus et al (1993) found trends away from psychological and sociological perspectives to biological ones in the two main American psychiatric journals over the last 20 years. This confirms a feeling that some have had for some time: that psychiatry is placing a greater emphasis on biology. In his 150th Anniversary Lecture to the Royal College of Psychiatrists, HRH the Prince of Wales (1991) suggested we must consider carefully the links between society and the 'scientific materialism' which dominates psychiatry. We argue that this mirrors the changes in our culture described above. If we accept the imperative of the individual over society, the triumph of individualism over collectivism, the latter with its rancorous overtones of Sovietism, then we should not be surprised if psychiatry reflects this. The mentally ill are over-represented in Galbraith's functional underclass. Biological psychiatry plays a dual role, seeking out the causes of mental illness with the aspiration of cure, and, at the same time, absolving society of any responsibility for mental illness. This is not to deny the value of neuroscience, nor do we claim that mental illness is simply an epiphenomenon of social and political disadvantage, but we have unwittingly devalued the importance of social factors in relation to mental illness. Unemployment, poor housing, homelessness, poverty, racial discrimination, are assumed to be irrelevant. The fault is seen as that of the individual. We are excused from asking awkward questions of ourselves and our political leaders.

\section{Conclusions}

We may now begin to understand why those who use mental health services are disillusioned. Users complain that all we have to offer is medication, when what they want is a job or decent housing. We take experiences rooted in social adversity and extract from them only those aspects of importance to us, the symptoms of mental illness. There is no sharing of languages, no common tongue with which to forge a genuine understanding. We should not be surprised if this results in alienation, not in the Marxist sense, but arising from a disjunction between subjective experience of the patient and the interpretation of that experience by the psychiatrist. Clinical psychiatry misappropriates that experience to yield symptoms suited to its biological framework. Many users regard psychiatry as an alien tongue in opposition to the languages that they want to describe their problems. Our failure to acknowledge the social contexts of mental illness, our insistence that these conditions require treatment and cure, imposes a deep split upon users. When our training was truly eclectic, we had the power to help the individual through a synthesis of biological, psychological and social languages. Now we are in danger of becoming crippled, unable to help through our blind devotion to biology at the expense of all else. The locus of care may have moved, but our explanatory models have not. As the care of those suffering from mental illness has shifted into a hostile, uncaring society, we pursue 
explanations of these illnesses that are remote from the reality of the experience of those who suffer. If this is to change we must develop models of mental illness that reflect the complexity of phenomena drawn out of individual responses to social adversity. This has implications both for the content of post-graduate training courses, as well as who should be involved in the training of psychiatrists. We must listen more carefully to the voices of our patients by according them a prominent role in our training.

\section{Acknowlodgement}

We express our gratitude to members of the Britich and Dutch User Movements who have helped to shape these ideas. In particular, we are grateful to Ron Coleman and the Hearing Voices Network.

\section{Roferences}

BARTLEY, M. (1994) Unemployment and in health: understanding the relationship. Journal of Epidemiology and Commenity Health, 48, 333-337.

BRUCB, M. L., TAXEUCF, D. T. \& LEAF, P. J. (1991) Poverty and poychiatric status: longitudinal evidence from the New Haven Epidemiological Catchment Area Study. Archives of General Psychiatry, 48, 470-474.

Cimparu, P. (1993) Mental health servicen - the user's view. British Medical Joumal, 306, 848-850.

Cohien, C. I. \& Thomarson, K. S. (1992) Homeless mentally ill, or mentally ill homeless? American Journal of Psychiatry, 149, 816-823.

P. Thomas, FRCPeych, Academic Sub-department of Psychological Medicine, University of Wales College of Medicine; Martus Romme, MD, Section of Social Psychiatry and Psychiatric Epidemiology, University of Limburg, P.O. Box 616, 6200 MD Maastricht, The Netherlands; Jacobus A. Hamelijnck, MD, Hergest Unit, Ysbyty Gwynedd

Correspondence: Dr P. Thomas, Department of Psychological Medicine, Hergest Unit, Ysbyty Gwynedd, Bangor LL57 2PW, Wales

(First received 6 February 1996, final revision 17 April 1996, accepted 19 April 1996)
Corb, J. W. (1991) "Difficult to place" peychiatric patients: The game of pass the parcel must stop. British Medical Journal, 302, 603-604.

Dres, C. (1987) Compulsory treatment in the community for the mentally ill? British Medical Joumal, 295, 991-992.

RnmaN, N. (1995) Anti-therapeutic community mental health law. British Medical Journal, 310, 1081-1082.

Galosumt, J. K. (1992) The Cultwre of Contentment. London: Sinclair-Stevenson.

Giocs, J. A. \& CoOpER, J. E. (1987) Ecological structure and the distribution of echizophrenia and affective psychoses in Nottingham. British Journal of Psychiatry, 151, 627-633.

HRH This PrnNcr of Wales (1991) Lecture, as Patron, to the Royal Collewe of Pyychiatriats, Brighton, Friday Sth July, 1991. British Joumal of Psychiatry, 199, 763-768.

JONEs, K. (1991) The culture of the mental hospital. In 150 years of British Psychiatry (eds G. Berrios \& H. Freeman). London: Gakkell.

Josery Rownmes FoundanoN (1995) Inquiry into Income and Wealth. London: Joeeph Rowntree Foundation.

LAM, H. R. (1992) Is it time for a moratorium on deinstitutionalisation? Hospital and Community Psychiatry, 43, 669.

Lewrs, A. (1936) Melancholia: Prognostic study and case material. Journal of Mental Science, 82, 488-588.

Pambroxe, L. (1993) Surviving poychiatry. Nursing Times, 87, 29 32.

3raus, H. A., Henderson, B., BlackwOOd, D., et al (1993) Treads in research in two seneral poychiatric journals in 1969-1990: Research on research. American Journal of Psychiatry, 150, 135-142.

Pamo, G., Henderson, L \& Mcl aught on, G. (1994) Mass Media Representations of Mental Health/Illness. Report For Health Bducation Board of Scotland by Glasgow University Media Group.

Roches, A., PLonn, D. \& LACEY, R. (1993) Experiencing

Thornucroft, G., Marcoluus, O. \& Jones, D. (1992) The TAPS project. 6: New long-stay poychiatric patients and social deprivation. British Journal of Psychiatry, 161, 621-624.

WARNis, R. (1985) Recovery from Schizophrenia: Psychiatry \& Political Economy. London: Routledge \& Kegan Paul Psychiatry: Users' Views of Services. London: Macmillan. 